\title{
"PRE-OPERATIVE PREDICTORS OF DIFFICULT LAPAROSCOPIC CHOLECYSTECTOMY; COMPARISONS OF TWO SCORING SYSTEMS. A SINGLE CENTER PROSPECTIVE STUDY"
}

Hari Gopal Vyas ${ }^{1}$, Vimal Bhandari², Saurabh³ ${ }^{3}$ Pawan Tiwari ${ }^{4}$, Mohit Singh ${ }^{5}$

\section{HOW TO CITE THIS ARTICLE:}

Hari Gopal Vyas, Vimal Bhandari, Saurabh, Pawan Tiwari, Mohit Singh. "Pre-operative predictors of difficult laparoscopic cholecystectomy; comparisons of two scoring systems. A single center prospective study". Journal of Evolution of Medical and Dental Sciences 2013; Vol. 2, Issue 41, October 14; Page: 7855-7862.

ABSTRACT: INTRODUCTION: Laparoscopic Cholecystectomy has evolved as the standard of care for the treatment of Gall Stone disease over the past decade. Several patient and procedure related factors have been implicated in setting of failure to complete the procedure by minimal invasive method and various scores have been developed to precisely predict a Difficult Laparoscopic Cholecystectomy. AIMS: The present study was conducted to ascertain various patient related preoperative risk factors for conversion of laparoscopic Cholecystectomy to open method and to validate the Risk Score for conversion. SETTINGS \& DESIGN: A total of 100 patients with diagnosis of Gall Stone Disease admitted to our surgical Unit between October 2011 and April 2013 were assessed for various pre-determined risk factors and were accordingly categorized into three levels of anticipated difficulty according to RSCLO and our new scoring system. The patients were then subjected to Laparoscopic Cholecystectomy by the same surgical team and the procedure was then graded as difficult or not according to the pre-defined criteria. The findings were analysed by appropriate statistical analysis. RESULTS: Presence of factors like Male sex, history of attacks of acute cholecystitis, increased GB wall thickness, presence of supra-umbilical abdominal scar, obesity and a contracted GB were associated with a significantly higher rate of conversion to open method. RSCLO was found to correlate better with the outcome in this setting than our New Scoring System. CONCLUSION: Several patient related factors may be helpful in predicting a Difficult Laparoscopic Cholecystectomy pre-operatively. RSCLO Scoring system may be useful as a pre-operative tool to predict intra-operative difficulty during LC.

KEY WORDS: Difficult laparoscopic Cholecystectomy, RSCLO, pre-operative factors.

INTRODUCTION: Laparoscopic Cholecystectomy has evolved as the Gold Standard procedure for treatment of Gall Stone Disease. In approximately $2-15 \%$ of the patients failure to achieve the desirous aim mandates the conversion of the procedure to Open Method ${ }^{1}$. Various patient and procedural related factors have been implicated for this conversion. Extensive studies and various protocols have also been suggested to identify 'Difficult Laparoscopic Cholecystectomy' preoperatively. Previous attacks of acute cholecystitis, GB wall thickness, inability to delineate the anatomy and previous abdominal surgery are some of the factors that have been identified as potential risk factors for the conversion. The present study was conducted to ascertain patient related pre-operative risk factors for conversion of laparoscopic Cholecystectomy to open method and to validate the Risk Score for conversion. 


\section{ORIGINAL ARTICLE}

MATERIAL AND METHODS: A total of 100 patients $>12$ years of age of both sexes were enrolled in the study. The diagnosis of Gall Stone Disease was based on clinical and Ultrasonography findings. Patients with Carcinoma, CBD stone, acute cholecystitis, portal hypertension, pregnant patients and patients with known bleeding diathesis were excluded from the study. All the patients were preoperatively analyzed with a definite protocol of clinical history, physical examination, laboratory and Ultrasonographic findings. Patients were subsequently categorized into Mild Moderate and Severe difficulty according to RSCLO and our new scoring system. The level of difficulty was analyzed by adding up the number of pre-determined risk factors and each case was categorized as Mild Difficulty [Score: 1-3], Moderate Difficulty [4-6] and Severe Difficulty [7-8]. All the risk factor coefficient were added. As per RSCLO and the constant was added to the final scoring system. These patients were subsequently divided into five groups [Group 1-5] of conversion probability [Table-1]. Patients were then subjected to Laparoscopic Cholecystectomy and a detailed note of per-operative findings was made. The procedure was then graded as difficult or not according to the pre-defined criteria. A difficult Laparoscopic Cholecystectomy was defined according to any difficult in port placements or creation of pneumoperitoneum, any difficulty in dissection or adhesiolysis at the Calot's triangle, difficulty in gall bladder extraction or an operative time of more than 90 minutes. Operative time was calculated from insertion of the Verre's needle to closure of the umbilical port. Relevant data including clinical and radiological, for the proposed prospective study were obtained from all the patients followed by compilation, tabulation and thorough analysis of the pertaining variables along with appropriate statistical application including chi square test. The level of statistical significance was taken as probability (P) value less than or equal to 0.05.This data was analyzed using SPSS statistical software version 16.0.

RESULTS: The mean age of the patient population was 40.28 years [20-63 years; Males 52 years, Female 38 years]. Out of the 5 patients aged >60years one patient had difficult LC according to the laid RSCLO criteria while two patient each had mild to moderately difficult LC. On the contrary none of these patients had difficult LC according to our new scoring system [NSS] criteria while four had moderately difficult procedure. Out of the five patients having age as a risk factor for conversion, 2 patients had difficult intra-operative findings, 2 were converted to open cholecystectomy and 1 patient did not have any intra-operative difficulty $\left[\mathrm{X}^{2}=26.91, \mathrm{P}<0.05\right]$. A female preponderance was observed in the study population with $86 \%$ of the patients being females while males constituted only $14 \%$ of the total patients. Of the 14 male patients seven were graded into mild difficulty and remaining under moderate difficulty under RSCLO. Similarly according the new scoring system which we used in our study, seven patients each were categorized into mid and moderate difficulty respectively. Of these 14 patients, 2 patients (14.29\%) had to undergo conversion, 6 patients $(42.86 \%)$ had difficult laparoscopic cholecystectomy and rest 6 patients $(42.86 \%)$ had no intraoperative difficulty $\left[\mathrm{X}^{2}=12.37, \mathrm{P}<0.05\right]$. A total of 14 patients in our study had a history of attack of acute cholecystitis within three months of surgery [RSCLO: Mild=4, Moderate $=9$, severe $=1$; NSS: Mild=10, moderate $=4]$. Of these, one patient was converted to open procedure, 11 had difficulty intra-operatively while one patient had uneventful LC $\left[\mathrm{X}^{2}=32.61, \mathrm{P}<0.05\right]$. A GB Wall thickness of more than $4 \mathrm{~mm}$ was taken as a criterion for difficult LC. 16 patients of the total had GB wall thickened according to the criterion [RSCLO: Mild=1, Moderate=14, Severe=1; NSS: Mild=7, Moderate=9]. Three of these patients finally underwent conversion to open method while in rest 13 


\section{ORIGINAL ARTICLE}

patients intra-operative difficulty was noted $\left[\mathrm{X}^{2}=60.43, \mathrm{P}<0.05\right]$. Further, 18 patients had previous supraumbilical abdominal scar [RSCL0: Mild=11, Moderate=6, Severe=1; NSS: Mild=15, Moderate=3]. Intra-operatively of these 18 patients one had a conversion to open method, 7 patients had difficulty during the procedure while no difficulty was encountered in remaining ten patients. With reference to GB volume, 9 patients of the total 100 had contracted GB on pre-operative Ultrasonography [NSS: Mild=5, Moderate=4, Severe=Nil]. Seven of these had intra-operative difficulty while in the remaining two the procedure was converted to open method $\left[\mathrm{X}^{2}=33.58\right.$, $\mathrm{P}<0.05]$. Also, 15 patients had a stone size of more than $1.5 \mathrm{~cm}$ on pre-operative ultrasonography [NSS: Mild=11, Moderate=4]. 9 of these patients had a difficult procedure, one had a conversion to open method while no difficulty was encountered in remaining 5 patients $\left[\mathrm{X}^{2}=16.45, \mathrm{P}<0.05\right]$. Further, a BMI of $>30$ was taken as a risk factor for conversion in our study. Among the total patient population only 2 patients were obese [NSS: Moderate=2] and both had intra-operative difficult procedure $\left[\mathrm{X}^{2}=7.23, \mathrm{P}<0.05\right]$.

Overall in a total study population of 100 patients, 89 patients were graded under mild difficulty pre-operatively according to the new scoring system. Out of 89 patients, $16.9 \%(15$ patients) had intra-operatively while 74 patients did not have intra-operative difficulty. 11 patients were predicted to have moderate difficulty. 3 patients $(27.3 \%)$ were converted to OC while 7 patients $(63.6 \%)$ had intra-operative difficulty.1 patient $(9.1 \%)$ predicted to have moderate difficulty did not have any difficulty during laparoscopic cholecystectomy. No patient was graded under severe difficulty. The pre-operative predictions matched favorably with intra-operative findings. According to RSCLO, 83 patients were predicted pre-operatively to have mild difficulty, 16 patients to have moderate difficulty and 1 patient to have severe difficulty during laparoscopic Cholecystectomy. Intra-operatively the patient predicted to have severe difficulty was converted to open cholecystectomy, whereas out of 16 patients predicted to have moderate difficulty 2 patients $(12.5 \%)$ were converted to OC and 14 patients $(87.5 \%)$ had intra-operative difficulty. In 83 patients predicted to have mild difficulty 75 patients (90.4\%) did not have intra-operative difficulty, while 8 patients $(9.6 \%)$ had intra-operative difficulty. The result was found to be favorably significant.

DISCUSSION: Laparoscopic Cholecystectomy is less invasive than open method and has become the Gold Standard of care for the treatment of symptomatic Gall Stones over the past decade. Of the various advantages attached to the method some worth mentioning include less post-operative pain and discomfort decreased post-operative ileus, better cosmesis, early ambulation and a shortened hospital stay. Despite these, in approximately $2-15 \%$ of the patients the procedure needs to be converted to open method ${ }^{1}$. Recent clinical trials have been conducted to predict operative conditions and conversion rate of laparoscopic cholecystectomy from pre-operative clinical, laboratory and ultrasonographic findings. However actual operative conditions are too complicated to be evaluated by a single factor and should be evaluated on the basis of all associated factors. One of the commonest reasons cited for conversion during LC was inability to delineate anatomy. Acute cholecystitis is being associated with increased difficulty and increased risk of conversion.

Of the many factors cited in the literature, age is considered one of the significant factors for a difficult LC. Reasons postulated include a long duration of disease and subsequent thickening and more contracted GB wall. In such cases the cystic duct becomes foreshortened and GB may be adherent to CBD. Fried et al. ${ }^{2}$ identified older age, (65 years and above) as a significant predictor of 


\section{ORIGINAL ARTICLE}

conversion. In their study of 1676 patients, 337 patients aged >65years had a conversion rate of 10.4\%. Similarly Pavlidiset $\mathrm{al}^{3}$ in 2007 in their study $(\mathrm{n}=1263)$ included cut-off age limit of 65years.They also found that there is a significant difference in conversion rate in patients with age $>65$ years $(12.38 \%)$ than those whose age was $<65$ years $(6.78 \%)$. In the present study, we too observed a higher chance of conversion to open method with advancing age. Male sex has also been identified as a risk factor for conversion in several series,2,3,4. In the present study Intra-operatively out of 14 male patients, 2 patients (14.29\%) were converted and 6 patients $(42.86 \%)$ had intraoperative difficulty. The intra-operative findings co-related significantly with the pre-operative predictive score. Further, Alponat et al. ${ }^{6}$ in their study found significant association of increased gall bladder wall thickness with conversion. In their study $(n=783)$ they reported a conversion rate of $20 \%$ out of 210 patients with thickened gall bladder wall $(>=3.5 \mathrm{~mm})$. Similar observations were also made in other study ${ }^{5}$ where a conversion rate of $32.8 \%$ was observed in patients with thickened GB Wall $(>4 \mathrm{~mm})$ in contrast to a conversion rate of $10.1 \%$ among those with normal GB wall. The intraoperative findings in our study also correlated significantly with predictive scoring system. A significantly higher rate of conversion was observed with an increase in the GB wall thickness $\left[\mathrm{X}^{2}=60.43, \mathrm{P}<0.05\right]$. Also recent history of attacks of acute cholecystitis has been known to have a significantly higher chance of conversion to open procedure. The conversion rate found during our study was $7.1 \%$ in patients with history of acute cholecystitis whereas in patients without the risk factor it was $2.33 \%$. Similar observations were also made by other authors 2 , 3, 7. A contracted GB follows a series of multiple attacks of inflammation and subsequent adhesions in the region of Calot's triangle. For this reason a contracted GB has been quoted to be potential risk factor for higher conversion rates ${ }^{8,9,10}$. Similar findings were also encountered in this study. While Akagolu et al.8in their study $(n=253)$ on patients with sclero-atrophic gall bladders reported difficulty with dense adhesions in $68.1 \%$ patients of which $23.1 \%$ patients had to undergo conversion to open Cholecystectomy we too observed almost comparable rate of conversion [22\%] in presence of low GB volume. A history of upper abdominal surgery in the past may lead to difficulty in creation of pneumoperitoneum secondary to formation of dense adhesions and hence presence of a supraumbilical abdominal scar was taken as an influential factor for a higher chance of conversion to open procedure in our study. A total of 18 patients in this study had a supra-umbilical scar. On intraoperative evaluation 7 patients $(42.45 \%)$ had intra-operative difficulty with a conversion rate of $5.56 \%$. The pre-operative scoring matched favorably with the intra-operative findings in this setting. Similar observations were also quoted by Kaplan et al. ${ }^{11}$ however the higher incidence of conversion [66.66\%] reported in their series may be attributed to their large study population and small number of patients with supra-umbilical scar. In a similar study by Botaitis et al ${ }^{12}(\mathrm{n}=2097)$ reported previous supra-umbilical surgery as an important predictor of conversion. They reported a conversion rate of $50 \%$ out of 78 patients with previous upper abdominal surgery. Correlation of chance of conversion with regard to stone size has been studied in various series as well ${ }^{13,14}$. While Saber et al $^{14}$ reported stone $>1 \mathrm{~cm}$ size to be a predictor of difficult LC, Verma et al ${ }^{13}$ large stone size in cases of single gall stones correlated with a higher conversion rate. In the present study we too observed a significantly higher rate of conversion with stone size $>1.5 \mathrm{~cm}$. Further, both of the obese

patients in our study had difficult surgery. Statistically significant association of obesity with a higher chance of conversion to open method has also been observed in several other series ${ }^{2,3,15}$. 
In addition RSCLO was found to be a better pre-operative assessment tool for prediction of intra-operative difficulty than our new scoring system and hence the authors suggest that RSCLO may be applied to all the patients undergoing elective laparoscopic cholecystectomy to preoperatively assess the intra-operative difficulty and take further steps accordingly.

CONCLUSION: Several patient related factors on pre-operative clinical examinations and imaging studies may guide the astute clinician to predict a 'Difficult Laparoscopic Cholecystectomy' and henceforth a higher chance of conversion to open method. RSCLO Scoring system correlates well with the outcome in this setting and hence may be useful as a pre-operative tool to predict intraoperative difficulty during L.C.

\section{ABBREVIATIONS:}

$\begin{array}{llllll}\text { GB: } & \text { GALL BLADDER } & & & & \\ \text { CBD: } & \text { COMMON BILE DUCT } & & & & \\ \text { LC: } & \text { LAPAROSCOPIC CHOLECYSTECTOMY } & & & \\ \text { OC: } & \text { OPEN CHOLECYSTECTOMY } & & & \\ \text { RSCLO: } & \text { RISK SCORING FOR CONVERSION } & \text { FROM } & \text { LAPAROSCOPIC } & \text { TO OPEN } \\ & \text { CHOLECYSTECTOMY } & & & & \\ \text { NSS: } & \text { NEW SCORING SYSTEM } & & & \end{array}$

\section{BIBLIOGRAPHY:}

1. Kama NA, Kologlu M, Doganay M, Reis E, Athi M, Dolapci M. A Risk Score for Conversion from Laparoscopic To Open Cholecystectomy. Am J Surgery 2001;181:520-25

2. Fried GM, Barkeen J S, Singhmun H H, Factors determining conversion to laparotomy in laparoscopic cholecystectomy. Am j Surg1994;167:35-39

3. Pavlidis TE, Marakis GN, Balles K, Symemidis N, Psauas K, Rapailidis S, Karvounais D, Sakantemis AK. Risk Factors Influencing Conversion of Laparoscopic To Open Cholecystectomy. Journal of Laparoendoscopic\& Advanced Surgical Techniques. part A 2007, 17(4):414-8

4. Kanaan S A, Murayama K M, Merriam L T Risk factors for conversion of laparoscopic to open cholecystectomy. J of Surg Research 2002;106;20-24

5. Rosen M, Broody F, Ponsky J. Predictive factors for conversion of Laparoscopic cholecystectomy. Am J Surgery 2002;184;254-258

6. Alponat A, Kum CK, Koh BC. Predictive factors for conversion of laparoscopic cholecystectomy. World J Surgery 1997;21;629-33

7. Gabriel R, Kumar S, Shrestha A. Evaluation of predictive factors for conversion of laparoscopic cholecystectomy. Kathmandu University Medical Journal (2009), Vol. 7, No. 1, Issue 25, 26-30

8. Musa AKOGLU, Metin ERCAN, E. Birol BOSTANCI, Zafer TEKE, Erkan PARLAK. Surgical Outcomes of Laparoscopic Cholecystectomy in Sclero-atrophic Gallbladders. Turk J Gastroenterol 2010; 21 (2): 156-162 
9. PawanLal, P N Agarwal, Vinod Kumar Malik, AL Chakrawarti. A Difficult Laparoscopic Cholecystectomy That Requires Conversion to Open Procedure Can Be Predicted by Preoperative Ultrasonography JSLS. 2002 Jan-Mar; 6(1): 59-63.

10. Janson S, Jorgensen M B, Caplchorn J, Hunt D. Preoperative ultrasound to predict conversion in laparoscopic cholecystectomy. Surgical Laparoscopy And Endoscopy 1997; vol 7; number 2:121-23

11. Mehmet KAPLAN, Bülent SALMAN, Halil Ibrahim IYIKÖSKER, HüseyinCahitLaparoscopic Cholecystectomy. The New Of Medicine 2007;24:146-151

12. S Botaitis, M Pitiakoudis, S Perente, G Tripsianis, A Polychronidis, CSimpoulos. Laparoscopic cholecystectomy in acute cholecystitis: An analysis of the risk factors. S Afr J Surg2012; 50(3):62-70. .

13. Verma G R, Bose S M, Wig J D. Pericholecystic adhesions in single vs multiple gall stones and their consequences for LC. J Laparoscopic Adv Surg Tech. 2001; vol 11, no-5;275-79

14. Alan A. Saber. Preoperative Clinical and Ultrasonic Parameters Predicting Conversion from Laparoscopic Cholecystectomy to Open Cholecystectomy. Tikrit Medical Journal 2007; 13(2):1-5

15. Takegami K, Sata N, Kawaguchi Y, Kubota Y. A New Preoperative Grading System For Predicting The Operative Conditions For Abdominal Wall-lifting Laparoscopic Cholecystectomy. Surg Today. 2002; 32(2):129-33.

CONFLICTS OF INTEREST: NIL

PLACE OF STUDY: VARDHAMAN MAHAVIR MEDICAL COLLEGE AND SAFDARJANG HOSPITAL AUROBINDO MARG, NEW DELHI [INDIA]: 110029.

\begin{tabular}{|c|c|c|}
\hline RISK FACTOR & VARIABLES & CO-EFFICIENTS \\
\hline \multirow{2}{*}{ SEX } & MALE & 11 \\
\cline { 2 - 3 } & FEMALE & 0 \\
\hline \multirow{2}{*}{ ABDOMINAL TENDERNESS } & PRESENT & 9 \\
\cline { 2 - 3 } & ABSENT & 0 \\
\hline \multirow{2}{*}{ P.S.U.S } & PRESENT & 8 \\
\cline { 2 - 3 } & ABSENT & 0 \\
\hline \multirow{2}{*}{ GB WALL THICKNESS } & $>=4 \mathrm{MM}$ & 13 \\
\cline { 2 - 3 } & $<4 \mathrm{MM}$ & 0 \\
\hline \multirow{2}{*}{ AGE } & $>=60$ YEARS & 5 \\
\cline { 2 - 3 } & $<60$ YEARS & 0 \\
\hline \multirow{2}{*}{ ACUTE CHOLECYSTITIS } & PRESENT & 15 \\
\cline { 2 - 3 } & ABSENT & 0 \\
\hline \multicolumn{2}{|c|}{ CONSTANT } & \multicolumn{2}{|c}{} \\
\hline \multicolumn{2}{|c|}{ TABLE 1: RISK SCORING ACCORDING TO RSCLO } \\
\hline \multirow{2}{*}{. }
\end{tabular}




\section{ORIGINAL ARTICLE}

\begin{tabular}{|l|c|c|}
\hline \multicolumn{1}{|c|}{ RISK FACTOR } & \multicolumn{2}{|c|}{ POINTS } \\
\hline \multirow{2}{*}{ Age } & $=>60$ YEARS & 1 \\
\cline { 2 - 3 } & $<60$ YEARS & 0 \\
\hline \multirow{2}{*}{ Sex } & MALE & 1 \\
\cline { 2 - 3 } & FEMALE & 0 \\
\hline \multirow{2}{*}{ H.O.A.C. } & PRESENT & 1 \\
\cline { 2 - 3 } & ABSENT & 0 \\
\hline \multirow{2}{*}{ B.M.I. } & $=>30$ & 1 \\
\hline \multirow{2}{*}{ P.S.U.S. } & $<30$ & 0 \\
\hline \multirow{2}{*}{ Gall Bladder Status } & PRESENT & 1 \\
\cline { 2 - 3 } & ABSENT & 0 \\
\hline \multirow{2}{*}{ Gall Bladder Thickness } & contracted & 1 \\
\cline { 2 - 3 } & distended & 0 \\
\hline \multirow{2}{*}{ Stone size } & $=>4 \mathrm{~mm}$ & 1 \\
\cline { 2 - 3 } & $<4 \mathrm{~mm}$ & 0 \\
\cline { 2 - 3 } & $>1.5 \mathrm{~cm}$ & 1 \\
\cline { 2 - 3 } & $<1.5 \mathrm{~cm}$ & 0 \\
\hline
\end{tabular}

Table 2: The risk factors according to New Scoring System

\begin{tabular}{|ll|l|}
\hline & $\begin{array}{c}\text { GROUPS FOR CONVERSION } \\
\text { PROBABILITY }\end{array}$ & $\begin{array}{c}\text { CATEGORIZATION OF RSCLO GROUPS } \\
\text { ACCORDING TO LEVEL OF DIFFICULTY }\end{array}$ \\
\hline 1. & GROUP 1: -20 TO -11 & MILD DIFFICULTY: GROUP 1 AND 2 \\
2. & GROUP 2: -10 TO -1 & \\
3. & GROUP 3: 0 TO 9 & MODERATE DIFFICULTY: GROUP 3 AND 4 \\
4. & GROUP 4: 10 TO 19 & \\
5. & GROUP5: $>19$ & SEVERE DIFFICLUTY: GROUP 5 \\
\hline \multicolumn{2}{|r}{ Table: 3} \\
\hline
\end{tabular}

\begin{tabular}{|c|c|c|c|}
\hline \multicolumn{2}{|c|}{} & No of patients & percent \\
\hline \multirow{4}{*}{ Difficulty Grade } & Mild Difficulty & 89 & 89 \\
\cline { 2 - 4 } & Moderate Difficulty & 11 & 11 \\
\cline { 2 - 4 } & Severe Difficulty & 0 & 0 \\
\cline { 2 - 4 } & Total & 100 & 100 \\
\hline
\end{tabular}

Table 4: Distribution of patients in various grades of difficulty according to new scoring system 


\begin{tabular}{|c|c|c|c|c|c|c|}
\hline & & & \multicolumn{3}{|c|}{ Intra operative Difficulty } & \multirow{2}{*}{ Total } \\
\hline & & & $\begin{array}{c}\text { Difficulty } \\
\text { Absent }\end{array}$ & $\begin{array}{c}\text { Difficulty } \\
\text { present }\end{array}$ & convert & \\
\hline \multirow{6}{*}{$\begin{array}{l}\text { Scoring } \\
\text { Difficulty }\end{array}$} & \multirow[b]{2}{*}{$\begin{array}{l}\text { mild } \\
\text { difficulty }\end{array}$} & No of patients & 74 & 15 & 0 & 89 \\
\hline & & $\begin{array}{c}\text { \% within } \\
\text { scoring } \\
\text { difficulty }\end{array}$ & $83.10 \%$ & 16.9 & $0 \%$ & 100 \\
\hline & \multirow[b]{2}{*}{$\begin{array}{l}\text { Moderate } \\
\text { difficulty }\end{array}$} & No of patients & 1 & 7 & 3 & 11 \\
\hline & & $\begin{array}{c}\text { \% within } \\
\text { scoring } \\
\text { difficulty }\end{array}$ & $9.10 \%$ & $63.60 \%$ & $27.30 \%$ & $100.00 \%$ \\
\hline & \multirow[b]{2}{*}{$\begin{array}{c}\text { Severe } \\
\text { Difficulty }\end{array}$} & No of patients & 0 & 0 & 0 & 0 \\
\hline & & $\begin{array}{l}\text { \% within } \\
\text { scoring } \\
\text { difficulty }\end{array}$ & $0 \%$ & $0 \%$ & $0 \%$ & $0 \%$ \\
\hline
\end{tabular}

$$
\mathrm{X}^{2}=41.171, \mathrm{P}<0.05
$$

\section{AUTHORS:}

1. Hari Gopal Vyas

2. Vimal Bhandari

3. Saurabh

4. Pawan Tiwari

5. Mohit Singh

\section{PARTICULARS OF CONTRIBUTORS:}

1. Professor \& Contributor, Department of Surgery, Vardhman Mahaveer Medical College \& Safdarjang Hospital, New Delhi.

2. Associate Professor \& Contributor, Department of Surgery, Vardhman Mahaveer Medical College \& Safdarjang Hospital, New Delhi.

3. P.G. Student \& Contributor, Department of Surgery, Vardhman Mahaveer Medical College \& Safdarjang Hospital, New Delhi.
4. Assistant Professor \& Contributor, Department of Surgery, Vardhman Mahaveer Medical College \& Safdarjang Hospital, New Delhi.

5. Assistant Professor \& Contributor, Department of Surgery, Vardhman Mahaveer Medical College \& Safdarjang Hospital, New Delhi.

\section{NAME ADDRESS EMAIL ID OF THE CORRESPONDING AUTHOR:}

Dr. Hari Gopal Vyas, 1227, Sector A, Pocket A, Vasant Kunj, New Delhi - 110070.

Email - premharidpac@yahoo.co.in

Date of Submission: 27/09/2013.

Date of Peer Review: 28/09/2013.

Date of Acceptance: 01/10/2013.

Date of Publishing: 08/10/2013 